\title{
Saturated fat supplementation interacts with dietary forage neutral detergent fiber content during the immediate postpartum period in Holstein cows: Energy balance and metabolism
}

\author{
P. Piantoni, A. L. Lock, and M. S. Allen ${ }^{1}$ \\ Department of Animal Science, Michigan State University, East Lansing 48824
}

\begin{abstract}
Forty-eight multiparous cows were used in a randomized complete block design experiment with a $2 \times 2$ factorial arrangement of treatments to determine the interaction between a highly saturated free FA supplement (SFFA) and dietary forage NDF (fNDF) content on energy balance and metabolic responses in postpartum cows. Treatment diets were offered from 1 to 29 $\mathrm{d}$ postpartum and contained 20 or $26 \%$ fNDF and 0 or 2\% SFFA (Energy Booster 100; 96.1\% FA: $46.2 \%$ C18:0, and 37.0\% C16:0). Overall, low fNDF versus high fNDF and $2 \%$ SFFA versus 0\% SFFA increased digestible energy intake (DEI; 67.5 vs. $62.2 \mathrm{Mcal} / \mathrm{d}$ and 68.1 vs. $61.6 \mathrm{Mcal} / \mathrm{d}$, respectively). The low fNDF diet with SFFA increased energy balance compared with the other treatments early during the treatment period, but treatment differences diminished over time. Overall, low fNDF versus high fNDF diets and $2 \%$ SFFA versus $0 \%$ SFFA improved energy balance $(-13.0$ vs. -16.3 $\mathrm{Mcal} / \mathrm{d}$ and -12.0 vs. -17.3 , respectively) decreasing efficiency of utilization of DEI for milk (milk $\mathrm{NE}_{\mathrm{L}}$ / DEI; 0.575 vs. 0.634 and 0.565 vs. 0.643 ). Low fNDF diets increased plasma insulin (308 vs. $137 \mu \mathrm{g} / \mathrm{mL}$ ) and glucose concentrations (50.5 vs. $45.7 \mathrm{mg} / \mathrm{dL}$ ) and decreased plasma nonesterified FA (606 vs. $917 \mu \mathrm{Eq} / \mathrm{L}$ ) and $\beta$-hydroxybutyrate (9.29 vs. $16.5 \mathrm{mg} / \mathrm{dL}$ ) concentrations and liver triglyceride content. Compared with $0 \%$ SFFA, $2 \%$ SFFA decreased plasma nonesterified FA concentration during the first week postpartum (706 vs. $943 \mu \mathrm{Eq} / \mathrm{L}$ ) and tended to decrease plasma nonesterified FA overall throughout the treatment period, but did not affect liver triglyceride content. During a glucose tolerance test, $2 \%$ SFFA increased plasma insulin concentration more in the low fNDF diet (84.5 vs. $44.6 \mu \mathrm{IU} / \mathrm{mL}$ ) than in the high fNDF $\operatorname{diet}(40.4$ vs. 38.0 $\mu \mathrm{IU} / \mathrm{mL}$ ). After glucose infusion, $2 \%$ SFFA increased insulin area under the curve by $64 \%$ when included in the low fNDF diet, but only by $5.2 \%$ when included
\end{abstract}

Received August 28, 2014.

Accepted December 15, 2014.

${ }^{1}$ Corresponding author: allenm@msu.edu in the high fNDF diet. Even though 2\% SFFA did not affect weekly plasma insulin concentration, it increased plasma insulin baseline concentration before the tolerance tests. Supplementation of 2\% SFFA and low fNDF diets increased DEI and improved energy balance, but decreased apparent efficiency of utilization of DEI for milk production. Fat supplementation affected energy partitioning, increasing energy balance and decreasing body condition score loss, especially in the lower fNDF diet. The decrease in body condition score loss observed was likely related to an increase in plasma insulin concentration. Feeding SFFA in a low fNDF diet during the first $29 \mathrm{~d}$ postpartum might have primed the cows to limit fat mobilization at the expense of milk.

Key words: dietary forage neutral detergent fiber, energy balance, free fatty acid, glucose and insulin tolerance tests

\section{INTRODUCTION}

Adaptation to the rapid increase in energy demand at the onset of lactation is challenging for dairy cows. Body reserves are mobilized around parturition because plasma insulin concentration (Zachut et al., 2013) and insulin sensitivity of extra-hepatic tissues is low (Bell, 1995). Increased mobilization of body reserves results in increased plasma NEFA concentration (González et al., 2011). Control of feed intake is likely dominated by hepatic oxidation of NEFA during the transition period (Allen et al., 2009), and increased NEFA supply to the liver can decrease energy intake and rumen fill, increasing the risk of displaced abomasum and acidosis (Allen and Piantoni, 2013). Elevated plasma NEFA concentrations can also alter immune function and might increase the risk of infectious diseases such as metritis (Lacetera et al., 2004; Sordillo et al., 2009). High plasma NEFA concentrations also increase risk of hepatic lipidosis (Rabelo et al., 2005), which can potentially affect liver function (González et al., 2011), decreasing gluconeogenesis, and milk yield.

To support energy demands at parturition and decrease mobilization of body reserves, diets with a 
higher energy density could be used. Higher dietary starch content or supplemental fats have been used for this purpose. However, not only the amount but also the form of the energy are important and can have different effects on performance. For example, a diet with lower forage to concentrate ratio $(\mathbf{F}: \mathbf{C})$ has the potential to increase energy intake and milk yield (Rabelo et al., 2003), decrease liver triglyceride (TG) content and plasma BHBA concentration, and increase plasma glucose and insulin concentrations during the first 3 wk postpartum (PP) when compared with a higher F:C diet (Rabelo et al., 2005). In contrast, a saturated free FA supplement fed during the first $6 \mathrm{wk}$ PP had no effect on net energy intake or energy balance (EBal) when compared with a control diet with no supplemental fat (Beam and Butler, 1998). Moreover, supplemental fat did not affect plasma insulin, glucose, and NEFA concentrations during the first $4 \mathrm{wk}$ PP (Beam and Butler, 1998).

Limited research is available on the interaction between forage NDF (fNDF) and supplementation of highly saturated fats during the PP period. Weiss and Pinos-Rodríguez (2009) showed that a saturated free FA supplemented $(2.3 \%$ of DM) in a low fNDF diet increased milk yield, but when supplemented in a high fNDF diet it increased BCS in early lactation cows (21 to 126 DIM). Unfortunately, only production responses were measured in that experiment, and therefore, the mechanism by which this interaction affected energy partitioning remains unknown. Moreover, because dietary treatments started early in lactation and not after parturition, it is not clear if these diets would have the same effect in immediate PP cows. Earlier, Jerred et al. (1990) fed a saturated prilled fat (at 5\% of DM) in diets with different F:C to cows from 5 to 100 DIM and observed no interaction between $\mathrm{F}$ : C and fat supplementation and no overall effect of the fat supplement on EBal or energy intake. However, fat supplementation increased energy intake and EBal during the first weeks of the experiment. Inconsistent results between Jerred et al. (1990) and Weiss and Pinos-Rodríguez (2009) might be related to the different DIM of the cows at the start of the experiments ( 5 vs. 21 DIM) and to the inclusion rates used ( 5 vs. $2.3 \%$ of diet DM).

Based on the aforementioned findings, our objectives were to determine the interaction between a highly saturated free FA supplement and dietary fNDF content on energy intake, EBal, and metabolic responses of dairy cows in the immediate PP period. We hypothesized that the saturated free FA supplement would increase EBal and plasma insulin concentration and decrease plasma NEFA and BHBA concentrations and liver TG content in the higher fNDF diet, and that it would decrease EBal and plasma insulin concentra- tion and increase liver TG content when added to the lower fNDF diet, consistent with the production results reported by Weiss and Pinos-Rodríguez (2009).

\section{MATERIALS AND METHODS}

This article is the second of 2 articles from an experiment that evaluated the use of a highly saturated ( $\geq 85 \%$ saturated) free FA supplement in rations with 2 fNDF contents in the immediate PP period. This article discusses the effect of these diets on energy intake, EBal, plasma metabolites and hormones, responses to glucose and insulin tolerance tests, and liver TG and glycogen contents. The companion paper (Piantoni et al., 2015) describes treatment effects on DMI, yield of milk and milk components, and digestibility of nutrients during the immediate PP period, and DMI and yields of milk and milk components during a carryover period, when all cows received a common diet.

\section{Animal Housing and Care}

All experimental procedures were approved by the Institutional Animal Care and Use Committee at Michigan State University (East Lansing). The experiment started on September 30, 2011, and finished on May 1, 2012. Each cow was housed in the same tiestall, assigned by parturition order, throughout the entire treatment period. Cows were fed once daily $(1000 \mathrm{~h})$ at $120 \%$ of expected intake and milked twice daily (0400 and $1430 \mathrm{~h}$ ). The amounts of feed offered and orts were weighed for each cow daily. Standard reproduction and health herd checks and breeding practices were maintained during the study.

\section{Design and Treatment Diets}

Forty-eight multiparous Holstein cows at the Michigan State University Dairy Field Laboratory were used in a randomized complete block design experiment with a $2 \times 2$ factorial arrangement of treatments with 12 cows per treatment. Cows were blocked by date of parturition (within $90 \mathrm{~d}$ ), BCS (up to 1 unit difference using a 5 -point scale, where $1=$ thin and $5=$ fat; Wildman et al., 1982), and previous lactation 305-d mature-equivalent milk production (MEq; within 5,500 $\mathrm{kg}$ ). The BCS used to block cows was the last measurement before parturition. Cows within each block were randomly assigned to treatment based on expected parturition date. All cows were in apparent good health at the beginning of the study, and treatment groups were not different in terms of 305-d MEq $(P=0.48)$, precalving BW $(P=0.39)$ and BCS $(P=0.33$; Piantoni et al., 2015). Treatment diets were offered from 1 to $29 \mathrm{~d}$ 
PP. Treatments contained 20 or $26 \%$ fNDF and 0 or $2 \%$ saturated free FA supplement (SFFA; Energy Booster 100; 96.1\% FA: 46.2\% C18:0 and 37.0\% C16:0; Milk Specialties Global, Eden Prairie, MN). Desired fNDF content of the treatment diets was attained by altering proportions of forages (alfalfa and corn silages and alfalfa hay) and concentrates (corn grain and soybean meal). The FA supplement was added at $2 \%$ of diet DM, replacing $2 \%$ of soyhulls in the $0 \%$ SFFA diets. Starch content was $\sim 24 \%$ for the low fNDF diets and $\sim 17.5 \%$ for the high fNDF diets. Treatment diets were mixed daily in a tumble-mixer and fed beginning the morning following parturition. The ingredient and nutrient composition of the diets fed as TMR, including close-up ration for reference, as well as a summary of all health incidents during the treatment period were reported in the companion article (Piantoni et al., 2015).

\section{Data and Sample Collection}

All samples and body measurements were collected or recorded on the same day of the week during the entire treatment period $(\mathrm{d} 5,12,19,26 \mathrm{PP})$, so all collection days are $\pm 3 \mathrm{~d}$ relative to the first day on the treatment diet. All data (milk yield, feed offered and refused, BW, and BCS) were recorded and samples (milk, feces, feed ingredients, and orts) were collected and stored as described in our companion article (Piantoni et al., 2015). Body condition was scored by 3 trained investigators on a 5 -point scale, as described by Wildman et al. (1982).

Blood samples were collected weekly by venipuncture of coccygeal vessels within $1 \mathrm{~h}$ before feeding on $\mathrm{d} 5$, 12,19 , and 26 PP. Blood was collected into 2 evacuated tubes, one containing potassium EDTA and the other containing potassium oxalate with sodium fluoride as a glycolytic inhibitor. Both were centrifuged at 2,000 $\times$ $g$ for 15 min immediately after sample collection, and plasma was harvested and stored at $-20^{\circ} \mathrm{C}$ until analysis. A sample containing EDTA was also preserved with benzamidine (0.05 $\mathrm{M}$ final concentration), a proteolytic inhibitor, to reduce glucagon degradation.

\section{Glucose and Insulin Tolerance Tests}

A glucose tolerance test (GTT) was conducted 13 $\pm 3 \mathrm{~d}$ PP according to Bradford and Allen (2007) and an insulin tolerance test (ITT) $14 \pm 3 \mathrm{~d}$ PP according to Smith et al. (2007). To minimize stress, all cows were fitted with a single jugular catheter (left or right jugular vein). Catheterization was performed $2 \mathrm{~d}$ before the GTT, according to Bradford et al. (2006). Catheter patency was checked daily until removed after the ITT. On the days of the tests, cows were blocked from feed at $0700 \mathrm{~h}$ and were not allowed access until tests were completed. For the GTT, a sterile solution of $50 \%$ dextrose (wt/vol) was administered by intrajugular bolus at a dose of $1.67 \mathrm{mmol}$ of glucose $/ \mathrm{kg}$ of BW over the course of $5 \mathrm{~min}$. Blood samples were collected from a jugular vein 10 min before infusion, immediately before infusion, and every $10 \mathrm{~min}$ through $120 \mathrm{~min}$, and at 150 and 180 min postinfusion. For the ITT, insulin (0.1 IU/ $\mathrm{kg}$ of BW) was infused over the course of $1 \mathrm{~min}$. Blood was sampled at $-30,-20,-10,0,2.5,5,7.5,10,12.5$, $15,17.5,20,25,30,45,60,90,120$, and 150 min relative to the insulin injection. Catheters were flushed with 25 $\mathrm{mL}$ of sterile $4.2 \% \mathrm{Na}$ citrate after glucose (GTT) and insulin (ITT) infusions and with 5 to $10 \mathrm{~mL}$ after each blood collection. Samples were processed as described above, within $1 \mathrm{~h}$ of collection.

\section{Liver Biopsies}

Liver tissue was collected by biopsy before feeding $19 \pm 3 \mathrm{~d}$ PP for determination of glycogen, TG, and total lipid contents. After local anesthetization with $2 \%$ lidocaine hydrochloride, a skin incision was performed and the biopsy instrument (14-gauge Vet-Core biopsy needles, Global Veterinary Products; New Buffalo, MI) inserted between the 10th and 11th ribs on a line between the olecranon and the tuber coxae on the right side. Ten samples of $\sim 20 \mathrm{mg}$ each were collected, snapfrozen in liquid nitrogen, and stored at $-80^{\circ} \mathrm{C}$ until further processing.

\section{Sample Analysis}

Feed, orts, and fecal samples were processed and analyzed as described in our companion article (Piantoni et al., 2015). Nutrient digestibility was determined as described in Piantoni et al. (2015), using indigestible NDF as the internal marker. Energy intakes and balance were calculated weekly using equations (NRC, 2001) according to Harvatine and Allen (2006).

Weekly plasma samples were analyzed in duplicate. Commercial kits were used to determine plasma concentrations of insulin (bovine insulin ELISA, \#10-120101, Mercodia, Uppsala, Sweden; intraassay CV: 6.5\%, interassay CV: 4.8\%), glucagon (Glucagon RIA kit no. GL-32K, Millipore Corp., St. Charles, MA; intraassay CV: $4.3 \%$, interassay CV: 5.9\%), NEFA [NEFA-HR (2) kit, Wako Chemicals USA Inc.; Richmond, VA; intraassay CV: 1.6\%, interassay: 6.2\%], TG (L-Type Triglyceride M kit, Wako Chemicals USA Inc.; intraassay CV: $7.2 \%$, interassay: $10.9 \%$ ), and BHBA (kit no. 2240, Stanbio Laboratory, Boerne, TX; intraassay CV: $2.7 \%$, interassay: $3.9 \%$ ). Plasma glucose concentration was analyzed using a glucose oxidase method (PGO 
Enzyme Product No. P7119, Sigma Chemical Co., St. Louis, MO; intraassay CV: $1.4 \%$, interassay CV: $1.3 \%$ ). Plasma samples from the GTT and ITT were analyzed in singlicate. Plasma insulin concentration was determined with a commercial kit (Coat-A-Count RIA kit; Siemens Healthcare Diagnostics, Deerfield, IL; GTT interassay CV: 11\%; ITT interassay CV: 10\%) and plasma glucose concentration was analyzed as described above for the weekly samples (GTT interassay CV: $2.0 \%$; ITT interassay CV: $2.9 \%$ ). Area under the curve (AUC) for glucose and insulin was calculated using the trapezoidal rule.

Liver samples were analyzed for glycogen, total lipids, and TG contents. Liver glycogen content was determined according to Hawk and Bergeim (1926), as modified by Bernal-Santos et al. (2003). Prior to glycogen determination, liver samples were freeze-dried and weighed to calculate liver DM. Total liver lipids were extracted according to Bligh and Dyer (1959). Liver TG content was determined as described by Rice et al. (2010). Absorbance was determined with a micro-plate reader (SpectraMax 340, Molecular Devices Corp., Sunnyvale, CA). Liver glycogen, total lipids, and TG are expressed as percentage of liver DM.

\section{Statistical Analysis}

All weekly data were analyzed using the MIXED procedure of SAS v.9.2 (SAS Institute Inc., Cary, NC) according to the following model with repeated measures:

$$
\begin{aligned}
\mathrm{Y}_{\mathrm{ijk} k m n} & =\mu+\mathrm{B}_{\mathrm{i}}+\mathrm{C}\left(\mathrm{B}_{\mathrm{i}} \mathrm{K}_{\mathrm{k}} \mathrm{S}_{\mathrm{l}}\right)_{\mathrm{j}}+\mathrm{K}_{\mathrm{k}}+\mathrm{S}_{\mathrm{l}}+\mathrm{K}_{\mathrm{k}} \mathrm{S}_{\mathrm{l}}+\mathrm{T}_{\mathrm{m}} \\
& +\mathrm{K}_{\mathrm{k}} \mathrm{T}_{\mathrm{m}}+\mathrm{S}_{\mathrm{l}} \mathrm{T}_{\mathrm{m}}+\mathrm{K}_{\mathrm{k}} \mathrm{S}_{\mathrm{l}} \mathrm{T}_{\mathrm{m}}+\mathrm{J}_{\mathrm{n}}+\mathrm{e}_{\mathrm{ij} \mathrm{jlm}},
\end{aligned}
$$

where $\mu=$ overall mean; $B_{i}=$ random effect of block (i $=1$ to 12$) ; \mathrm{C}\left(\mathrm{B}_{\mathrm{i}} \mathrm{K}_{\mathrm{k}} \mathrm{S}_{1}\right)_{\mathrm{j}}=$ random effect of cow $(\mathrm{j}=1$ to 4) within block and treatment diet; $K_{k}=$ fixed effect of fNDF ( $k=1$ to 2$) ; S_{1}=$ fixed effect of SFFA ( $1=1$ to 2); $\mathrm{K}_{\mathrm{k}} \mathrm{S}_{1}=$ interaction between fNDF and SFFA; $\mathrm{T}_{\mathrm{m}}=$ fixed effect of week ( $\mathrm{m}=1$ to 4$) ; \mathrm{K}_{\mathrm{k}} \mathrm{T}_{\mathrm{m}}=$ interaction between fNDF and week; $\mathrm{S}_{\mathrm{l}} \mathrm{T}_{\mathrm{m}}=$ interaction between SFFA and week; $\mathrm{K}_{\mathrm{k}} \mathrm{S}_{\mathrm{l}} \mathrm{T}_{\mathrm{m}}=$ interaction between fNDF, SFFA, and week; $J_{n}=$ random effect of Julian date; and $\mathrm{e}_{\mathrm{ijklmn}}=$ residual error. First-order autoregressive was the covariate structure used for analysis because it resulted in the lowest Bayesian information criterion for most of the variables measured. Interactions with time were removed from the model when nonsignificant, and a reduced model was used to determine treatment effects. However, all interactions were included in the tables for informational purposes.

Treatment differences within week were analyzed using the GLIMMIX procedure of SAS version 9.2 (SAS Institute Inc.) and the SLICE option. The model included the random effects of block and cow nested within block and treatment and the fixed effects of fNDF and SFFA and their interaction. The Bonferroni adjustment was applied to decrease the probability of type I error when multiple treatment means were compared. Liver parameters, responses to the GTT and ITT, and BW and BCS changes were analyzed using the MIXED procedure of SAS version 9.2 (SAS Institute Inc.) with the same model used in the GLIMMIX procedure.

Normality of the residuals was checked with normal probability and box plots and homogeneity of variances with plots of residuals versus predicted values. Significance was determined at $P \leq 0.05$ for main effects and $P \leq 0.10$ for interactions. Tendencies were determined at $P \leq 0.10$ for main effects and $P \leq 0.15$ for interactions. All data were included in the statistical analyses.

\section{RESULTS}

\section{Energy Intake and Energy Balance}

Overall, low fNDF and 2\% SFFA increased digestible energy intake (DEI; both $P \leq 0.01$; Table 1). Digestible energy intake increased over time for all 4 diets, and was highest for the low fNDF diet with $2 \%$ SFFA and lowest for the high fNDF diet with $0 \%$ SFFA during the entire treatment period (Figure 1A). The low fNDF diet with 0\% SFFA increased DEI at a higher rate during the last week of treatment (interaction $P=0.03$ ). The low fNDF diet with $2 \%$ SFFA increased EBal during the entire treatment period compared with the other 3 diets, but differences among treatments decreased over time (interaction $P=0.10$; Table 1; Figure 1B). Overall, low fNDF diets and 2\% SFFA increased EBal (both $P<0.05)$ and decreased efficiency of utilization of DEI for milk and production (both $P<0.05$; Table 1 ). The low fNDF with $2 \%$ SFFA tended to decrease BCS loss compared with the other diets (interaction $P=0.13$; Table 1; Figure 1C), and 2\% SFFA decreased BW loss compared with 0\% SFFA (Table 1; Figure 1D).

\section{Plasma Metabolites and Hormones}

No interactions between dietary fNDF content and SFFA for plasma metabolites and hormones were detected. The low fNDF treatment increased plasma insulin, insulin to glucagon ratio, and glucose concentrations (all $P \leq 0.001$ ) and decreased plasma NEFA and BHBA concentrations (both $P<0.001$ ), and tended to increase TG concentrations $(P=0.06)$ compared with the high fNDF treatment (Table 2). At the beginning of the PP, low fNDF diets increased glucagon concentration compared with high fNDF diets, but this difference 
Table 1. Effects of dietary forage NDF (fNDF) content and a saturated free FA supplement (SFFA) on DMI, milk yield, energy intake, energy balance, and efficiency of energy utilization of dairy cows during the postpartum period ( 1 to $29 \mathrm{~d}$ postpartum; $\mathrm{n}=48$ )

\begin{tabular}{|c|c|c|c|c|c|c|c|c|c|c|c|}
\hline \multirow[b]{2}{*}{ Item } & \multicolumn{2}{|c|}{$20 \% \mathrm{fNDF}$} & \multicolumn{2}{|c|}{$26 \% \mathrm{fNDF}$} & \multirow[b]{2}{*}{ SEM } & \multicolumn{6}{|c|}{$P$-value } \\
\hline & $\begin{array}{c}0 \% \\
\text { SFFA }\end{array}$ & $\begin{array}{c}2 \% \\
\text { SFFA }\end{array}$ & $\begin{array}{c}0 \% \\
\text { SFFA }\end{array}$ & $\begin{array}{c}2 \% \\
\text { SFFA }\end{array}$ & & fNDF & SFFA & $\begin{array}{c}\text { fNDF } \\
\times \text { SFFA }\end{array}$ & $\begin{array}{l}\mathrm{fNDF} \\
\times \text { time }\end{array}$ & $\begin{array}{l}\text { SFFA } \\
\times \text { time }\end{array}$ & $\begin{array}{c}\text { fNDF } \times \\
\text { SFFA } \\
\times \text { time }\end{array}$ \\
\hline DMI, kg/d & 23.6 & 24.2 & 20.8 & 23.0 & 0.743 & $<0.01$ & 0.04 & 0.25 & 0.79 & 0.61 & $<0.01$ \\
\hline Milk yield, $\mathrm{kg} / \mathrm{d}$ & 51.2 & 45.3 & 48.2 & 47.8 & 1.89 & 0.90 & 0.10 & 0.16 & 0.09 & 0.72 & 0.22 \\
\hline \multicolumn{12}{|l|}{ Energy intake, Mcal/d } \\
\hline $\mathrm{DE}^{1}$ & 65.0 & 70.0 & 58.1 & 66.2 & 2.16 & $<0.01$ & $<0.01$ & 0.40 & 0.76 & 0.69 & 0.03 \\
\hline $\mathrm{ME}^{2}$ & 55.0 & 59.9 & 49.3 & 56.7 & 1.88 & 0.01 & $<0.001$ & 0.45 & 0.75 & 0.72 & 0.04 \\
\hline $\mathrm{NE}_{\mathrm{L}}^{3}$ & 34.2 & 37.7 & 30.7 & 35.7 & 1.20 & 0.01 & $<0.001$ & 0.49 & 0.75 & 0.75 & 0.04 \\
\hline \multicolumn{12}{|l|}{ Production } \\
\hline $\mathrm{NE}_{\mathrm{L}}$ maintenance, ${ }^{4} \mathrm{Mcal} / \mathrm{d}$ & 11.4 & 11.0 & 10.7 & 10.9 & 0.281 & 0.14 & 0.65 & 0.33 & 0.05 & 0.78 & 0.79 \\
\hline Milk $\mathrm{NE}_{\mathrm{L}},{ }^{5} \mathrm{Mcal} / \mathrm{d}$ & 39.4 & 35.9 & 38.0 & 39.2 & 1.71 & 0.55 & 0.49 & 0.16 & 0.20 & 0.30 & 0.30 \\
\hline BW change ${ }^{6}$ & -110 & -84.9 & -126 & -107 & 10.7 & 0.06 & 0.03 & 0.79 & NA & NA & NA \\
\hline BCS change $^{6}$ & -0.816 & -0.490 & -0.950 & -0.903 & 0.090 & $<0.01$ & 0.04 & 0.13 & NA & NA & NA \\
\hline Energy balance, ${ }^{7} \mathrm{Mcal} / \mathrm{d}$ & -16.4 & -9.54 & -18.1 & -14.5 & 1.76 & 0.04 & $<0.01$ & 0.33 & 0.31 & 0.40 & 0.10 \\
\hline \multicolumn{12}{|l|}{ Efficiency } \\
\hline $\mathrm{NE}_{\mathrm{L}}$ milk/DE intake & 0.622 & 0.527 & 0.664 & 0.603 & 0.027 & 0.02 & $<0.01$ & 0.47 & 0.20 & 0.08 & 0.19 \\
\hline $\mathrm{NE}_{\mathrm{L}}$ production ${ }^{8} / \mathrm{DE}$ intake & 0.805 & 0.687 & 0.853 & 0.772 & 0.030 & 0.01 & $<0.001$ & 0.47 & 0.24 & 0.06 & 0.17 \\
\hline
\end{tabular}

${ }^{1}$ Digestible energy intake $=$ gross energy intake $(\mathrm{Mcal} / \mathrm{d}) \times$ gross energy digestibility.

${ }^{2}$ Metabolizable energy intake $=$ MEp (ME at production levels of intake; Mcal $/ \mathrm{kg}$ of DM; calculated according to NRC, 2001) $\times$ DMI $(\mathrm{kg} / \mathrm{d})$

${ }^{3}$ Net energy of lactation intake was calculated from DE through ME according to NRC (2001).

¿ $\quad{ }^{4} \mathrm{NE}_{\mathrm{L}}$ maintenance $(\mathrm{Mcal} / \mathrm{d})=0.08 \mathrm{Mcal} / \mathrm{kg} \times \mathrm{BW}(\mathrm{kg})^{0.75}(\mathrm{NRC}, 2001)$.

${ }^{5}$ Milk NE $\mathrm{L}(\mathrm{Mcal} / \mathrm{d})=$ milk yield $(\mathrm{kg} / \mathrm{d}) \times[($ fat $\% \times 0.0929)+($ true protein $\% \times 0.0563)+($ lactose $\% \times 0.0395)](\mathrm{NRC}, 2001)$.

$\stackrel{{ }^{6}}{0}$ Change measured between d 26 and precalving (Piantoni et al., 2015).

을 ${ }^{7}$ Energy balance $(\mathrm{Mcal} / \mathrm{d})=\mathrm{NE}_{\mathrm{L}}$ intake $(\mathrm{Mcal} / \mathrm{d})-\operatorname{milk~} \mathrm{NE}_{\mathrm{L}}(\mathrm{Mcal} / \mathrm{d})-\mathrm{NE}_{\mathrm{L}}$ maintenance requirement $(\mathrm{Mcal} / \mathrm{d})$.

$\stackrel{\mathbb{D}^{2}}{\stackrel{8}{\Sigma}} \quad \mathrm{NE}_{\mathrm{L}}$ production $=$ milk $\mathrm{NE}_{\mathrm{L}}$ plus $\mathrm{NE}_{\mathrm{L}}$ required for maintenance. 
A

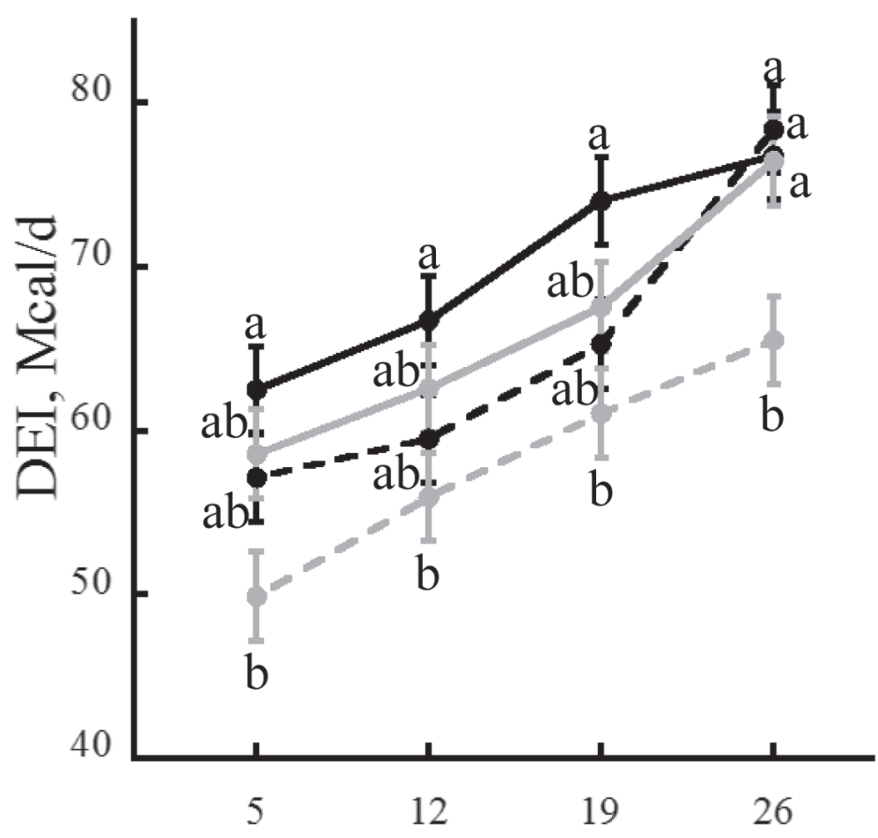

$\mathrm{C}$

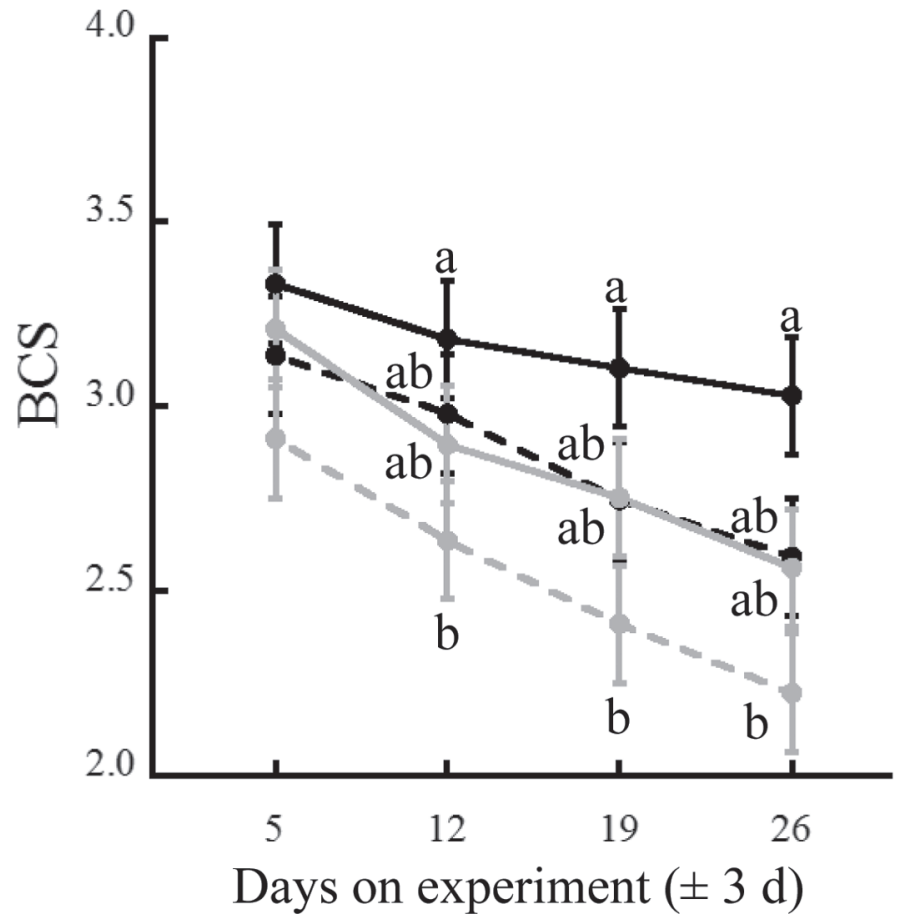

B

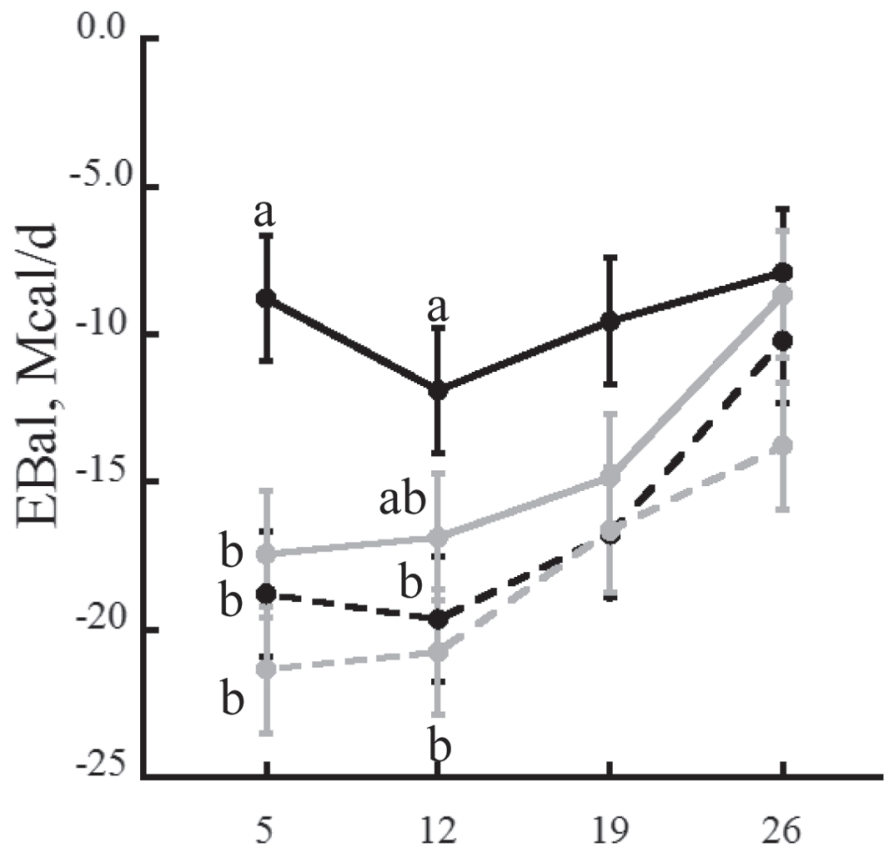

$\mathrm{D}$

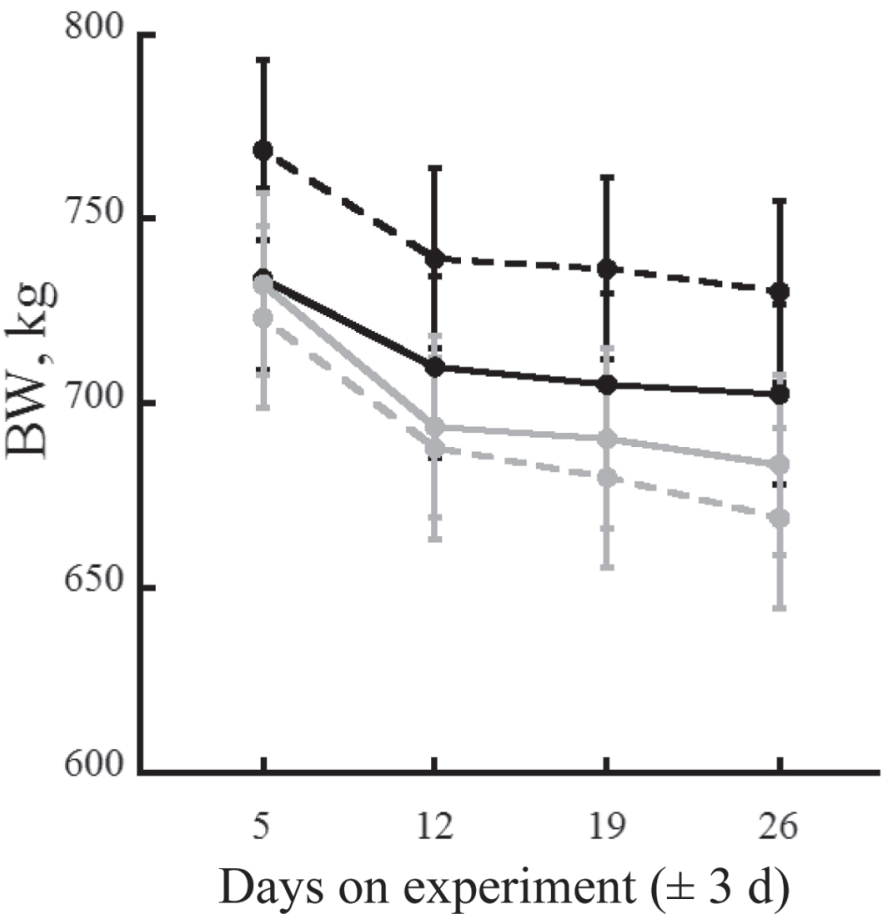

Figure 1. Effects of dietary forage NDF (fNDF) content and a saturated free FA supplement (SFFA) on (A) digestible energy intake (DEI), (B) energy balance (EBal), (C) BCS, and (D) BW over time during the postpartum period. Treatment diets were $20 \%$ fNDF $0 \%$ SFFA (black, broken line), $20 \%$ fNDF $2 \%$ SFFA (black, solid line), $26 \%$ fNDF $0 \%$ SFFA (gray, broken line), and $26 \%$ fNDF $2 \%$ SFFA (gray, solid line; $\mathrm{n}=$ 48). Different letters within a time point signify significant difference at $P \leq 0.05$. Interactions between fNDF, SFFA, and time were detected for DEI and EBal $(P<0.10)$. Interactions between SFFA and time and fNDF and time for BW and BCS, respectively, were detected (both $P$ $<0.10$ ). Values are LSM \pm SEM. Data for BCS and BW were presented in the companion paper (Piantoni et al., 2015). 
Table 2. Effects of dietary forage NDF (fNDF) content and a saturated free FA supplement (SFFA) on plasma metabolites and hormones of dairy cows during the postpartum period ( 1 to 29 d postpartum; $n=48$ )

\begin{tabular}{|c|c|c|c|c|c|c|c|c|c|c|c|}
\hline \multirow[b]{2}{*}{ Item } & \multicolumn{2}{|c|}{$20 \% \mathrm{fNDF}$} & \multicolumn{2}{|c|}{$26 \% \mathrm{fNDF}$} & \multirow[b]{2}{*}{ SEM } & \multicolumn{6}{|c|}{$P$-value } \\
\hline & $\begin{array}{c}0 \% \\
\text { SFFA }\end{array}$ & $\begin{array}{c}2 \% \\
\text { SFFA }\end{array}$ & $\begin{array}{c}0 \% \\
\text { SFFA }\end{array}$ & $\begin{array}{c}2 \% \\
\text { SFFA }\end{array}$ & & fNDF & SFFA & $\begin{array}{c}\mathrm{fNDF} \\
\times \mathrm{SFFA}\end{array}$ & $\begin{array}{l}\mathrm{fNDF} \\
\times \text { time }\end{array}$ & $\begin{array}{l}\text { SFFA } \\
\times \text { time }\end{array}$ & $\begin{array}{c}\mathrm{fNDF} \times \\
\mathrm{SFFA} \\
\times \text { time }\end{array}$ \\
\hline Insulin, $\mu \mathrm{g} / \mathrm{mL}$ & 262 & 353 & 129 & 145 & 45.9 & $<0.001$ & 0.25 & 0.42 & 0.32 & 0.31 & 0.34 \\
\hline Glucagon, pg/mL & 118 & 126 & 114 & 120 & 4.91 & 0.30 & 0.13 & 0.88 & 0.01 & 0.41 & 0.16 \\
\hline Insulin:glucagon & 2.21 & 2.83 & 1.12 & 1.23 & 0.338 & $<0.001$ & 0.29 & 0.45 & 0.55 & 0.33 & 0.35 \\
\hline BHBA, mg/dL & 8.95 & 9.62 & 15.0 & 17.9 & 1.99 & $<0.001$ & 0.32 & 0.53 & 0.16 & 0.16 & 0.48 \\
\hline Triglycerides, mg/dL & 5.81 & 7.19 & 5.22 & 6.33 & 0.421 & 0.06 & $<0.01$ & 0.72 & 0.55 & 0.05 & 0.73 \\
\hline
\end{tabular}

disappeared as time progressed (interaction $P=0.01$ ). Overall, $2 \%$ SFFA increased plasma TG concentration $(P<0.01)$ and tended to decrease plasma NEFA concentration $(P=0.06)$; the decrease in NEFA was more pronounced at the beginning than at the end of the treatment period (interaction $P=0.05$ ), and the increase in TG was observed during the whole treatment period except for d $12 \mathrm{PP}$ (interaction $P=0.05$ ). Compared with 0\% SFFA, 2\% SFFA decreased plasma NEFA concentration during the first week PP (706 vs. $943 \mu \mathrm{Eq} / \mathrm{L} ; P<0.05)$.

\section{Glucose and Insulin Tolerance Tests}

The low fNDF treatment increased plasma glucose baseline values and maximum concentration of glucose after glucose infusion and decreased the time required for plasma glucose concentration to return to baseline values $(P<0.01)$, decreasing plasma glucose AUC $(P$ $=0.03$ ) compared with high fNDF diets (Table 3). During the GTT, 2\% SFFA increased the time required for glucose to reach baseline concentration in the high fNDF diet and decreased it in the low fNDF diet (interaction $P=0.07$ ) but had no other effects on glucose responses. Low fNDF diets and 2\% SFFA increased maximum plasma insulin concentration after glucose infusion $(P \leq 0.05)$ and the rate at which this maximum concentration was reached (both $P=0.02$ ) but SFFA effects were greater in the low fNDF diets than in the high fNDF diets (both interactions $P<0.10$ ). Both low fNDF diets and $2 \%$ SFFA increased baseline insulin concentration on the day of the GTT (both $P<0.05$ ). Low fNDF diets increased insulin AUC after glucose infusion $(P=0.01)$, whereas $2 \%$ SFFA only tended to increase it $(P<0.10)$. Fat supplementation tended to interact with dietary fNDF content for insulin secretion: $2 \%$ SFFA increased insulin AUC by $64 \%$ when included in the low fNDF diet, but only by $5.2 \%$ when included in the high fNDF diet (interaction $P=0.12$ ).
During the ITT, low fNDF increased baseline plasma glucose concentration and the rate of decrease to its nadir compared with the high fNDF treatment (both $P<0.05)$. Fat supplementation decreased the absolute value of the AUC for glucose after insulin infusion $(P$ $=0.02$ ). The low fNDF diet with $2 \%$ SFFA increased baseline plasma insulin on the day of the ITT compared with the other diets (interaction $P=0.07$ ); overall, both the low fNDF diets and $2 \%$ SFFA increased baseline plasma insulin concentration (both $P \leq 0.05$ ). During the ITT, $2 \%$ SFFA decreased insulin time to baseline in the low fNDF but increased it in the high fNDF treatment (interaction $P<0.01$ ).

\section{Liver Glycogen, Total Lipids, and Triglyceride Contents}

Dietary fNDF content and SFFA did not interact to affect liver parameters measured on d 19 PP (Table 4). High fNDF diets tended to increase BCS loss $(P=$ 0.07 ) and increased DM percent and liver total lipids content (both $P<0.05$ ). High fNDF diets increased TG content by $42 \%$ compared with the low fNDF diets $(P=0.04)$. Even though $2 \%$ SFFA tended to increase both BW and BCS loss by d $19 \mathrm{PP}$ (both $P<0.10$ ), it did not affect DM percent or liver total lipids and TG contents. Liver glycogen content was not affected by treatment. Liver TG were positively related to plasma NEFA concentration at d $19 \mathrm{PP}\left(\mathrm{R}^{2}=0.52 ; P<0.0001\right.$; Figure $2 \mathrm{~A}$ ), and negatively related to the BCS change observed from parturition until d $19 \mathrm{PP}\left(\mathrm{R}^{2}=0.25 ; P\right.$ $<0.001$; Figure 2B).

\section{DISCUSSION}

\section{Digestible Energy Intake and Energy Balance}

Previous research suggests that feeding low-forage/ high-starch diets or saturated fats during the first 
Table 3. Effects of dietary forage NDF (fNDF) content and a saturated free FA supplement (SFFA) on glucose and insulin responses to glucose $(13 \pm 3 \mathrm{~d}$ postpartum) and insulin $(14 \pm 3 \mathrm{~d}$ postpartum) tolerance tests in dairy cows $(\mathrm{n}=48)$

\begin{tabular}{|c|c|c|c|c|c|c|c|c|}
\hline Item & $\begin{array}{c}0 \% \\
\text { SFFA }\end{array}$ & $\begin{array}{c}2 \% \\
\text { SFFA }\end{array}$ & $\begin{array}{c}0 \% \\
\text { SFFA }\end{array}$ & $\begin{array}{c}2 \% \\
\text { SFFA }\end{array}$ & SEM & fNDF & SFFA & $\begin{array}{c}\mathrm{fNDF} \\
\times \mathrm{SFFA}\end{array}$ \\
\hline \multicolumn{9}{|l|}{ Glucose tolerance test } \\
\hline \multicolumn{9}{|l|}{ Glucose } \\
\hline Baseline, $\mathrm{mg} / \mathrm{dL}$ & 49.5 & 50.1 & 45.1 & 43.1 & 1.80 & $<0.01$ & 0.70 & 0.48 \\
\hline Maximum ${ }^{1} \mathrm{mg} / \mathrm{dL}$ & 170 & 171 & 161 & 158 & 4.52 & 0.02 & 0.81 & 0.72 \\
\hline $\mathrm{AUC},{ }^{2} \min \times \mathrm{mg} / \mathrm{dL}$ & 3,488 & 3,371 & 3,772 & 3,965 & 206 & 0.03 & 0.85 & 0.44 \\
\hline \multicolumn{9}{|l|}{ Insulin } \\
\hline Baseline, ${ }^{3} \mu \mathrm{IU} / \mathrm{mL}$ & 1.57 & 2.74 & 1.03 & 1.52 & & & & \\
\hline Log-transformed & 0.195 & 0.438 & 0.014 & 0.183 & 0.094 & 0.02 & 0.03 & 0.68 \\
\hline Maximum, $\mu \mathrm{IU} / \mathrm{mL}$ & 44.6 & 84.5 & 38.0 & 40.4 & 10.7 & 0.02 & 0.05 & 0.07 \\
\hline Time to maximum, min & 15.0 & 15.0 & 14.2 & 12.5 & 1.45 & 0.23 & 0.55 & 0.55 \\
\hline Rate, $\min \times \mu \mathrm{IU} / \mathrm{mL}$ & 3.07 & 5.61 & 2.66 & 3.04 & 0.639 & 0.02 & 0.02 & 0.08 \\
\hline Minimum, mg/dL & 25.0 & 26.9 & 23.6 & 24.4 & 1.41 & 0.17 & 0.34 & 0.72 \\
\hline Time to minimum, min & 37.9 & 34.6 & 40.0 & 42.1 & 3.32 & 0.16 & 0.85 & 0.42 \\
\hline Rate, $\min \times \mathrm{mg} / \mathrm{dL}$ & -0.821 & -0.769 & -0.648 & -0.568 & 0.077 & 0.02 & 0.40 & 0.86 \\
\hline Time to baseline, $\min$ & 110 & 98.8 & 111 & 105 & 6.92 & 0.59 & 0.21 & 0.72 \\
\hline $\mathrm{AUC},{ }^{2} \mathrm{~min} \times \mathrm{mg} / \mathrm{dL}$ & $-2,034$ & $-1,561$ & $-1,834$ & $-1,518$ & 167 & 0.47 & 0.02 & 0.64 \\
\hline \multicolumn{9}{|l|}{ Insulin } \\
\hline Baseline, ${ }^{3} \mu \mathrm{IU} / \mathrm{mL}$ & 1.39 & 2.56 & 1.14 & 1.24 & & & & \\
\hline Log-transformed & 0.142 & 0.409 & 0.057 & 0.094 & 0.073 & $<0.01$ & 0.02 & 0.07 \\
\hline Maximum, $\mu \mathrm{IU} / \mathrm{mL}$ & 712 & 777 & 637 & 707 & 92.9 & 0.43 & 0.46 & 0.97 \\
\hline Time to maximum, min & 2.50 & 2.50 & 2.50 & 2.71 & 0.104 & 0.32 & 0.32 & 0.32 \\
\hline Rate, $\min \times \mu \mathrm{IU} / \mathrm{mL}$ & 284 & 309 & 254 & 259 & 35.0 & 0.25 & 0.66 & 0.77 \\
\hline Time to baseline, $\min$ & 118 & 85.0 & 101 & 115 & 6.76 & 0.32 & 0.17 & $<0.01$ \\
\hline $\mathrm{AUC},{ }^{2} \min \times \mu \mathrm{IU} / \mathrm{mL}$ & 9,518 & 9,066 & 8,368 & 9,056 & 745 & 0.37 & 0.85 & 0.38 \\
\hline
\end{tabular}

${ }^{1}$ Time to maximum plasma glucose concentration was 10 min for all cows.

${ }^{2}$ Area under the curve, calculated with the trapezoidal rule.

${ }^{3}$ For interpretation purposes, means were back-transformed from the log-transformed means showed in the following row.

Table 4. Effects of dietary forage NDF (fNDF) content and a saturated free FA supplement (SFFA) on liver glycogen, triglyceride, and total lipid contents of dairy cows $19 \pm 3$ d postpartum $(n=48)$

\begin{tabular}{|c|c|c|c|c|c|c|c|c|}
\hline \multirow[b]{2}{*}{ Item } & \multicolumn{2}{|c|}{$20 \%$ fNDF } & \multicolumn{2}{|c|}{$26 \% \mathrm{fNDF}$} & \multirow[b]{2}{*}{ SEM } & \multicolumn{3}{|c|}{$P$-value } \\
\hline & $\begin{array}{c}0 \% \\
\text { SFFA }\end{array}$ & $\begin{array}{c}2 \% \\
\text { SFFA }\end{array}$ & $\begin{array}{c}0 \% \\
\text { SFFA }\end{array}$ & $\begin{array}{c}2 \% \\
\text { SFFA }\end{array}$ & & fNDF & SFFA & $\begin{array}{l}\mathrm{fNDF} \\
\times \text { SFFA }\end{array}$ \\
\hline DM, \% & 29.2 & 28.9 & 31.7 & 31.9 & 1.29 & 0.03 & 0.95 & 0.85 \\
\hline Total lipids, $\%$ of DM & 30.3 & 30.0 & 40.4 & 38.4 & 3.69 & 0.02 & 0.76 & 0.82 \\
\hline Triglycerides, $\%$ of DM & 7.47 & 6.01 & 10.4 & 8.69 & 1.39 & 0.04 & 0.24 & 0.91 \\
\hline $\begin{array}{l}\text { BCS change, precalving to } 19 \mathrm{~d} \\
\text { postpartum }\end{array}$ & -0.629 & -0.410 & -0.708 & -0.639 & 0.088 & 0.07 & 0.09 & 0.37 \\
\hline
\end{tabular}


A

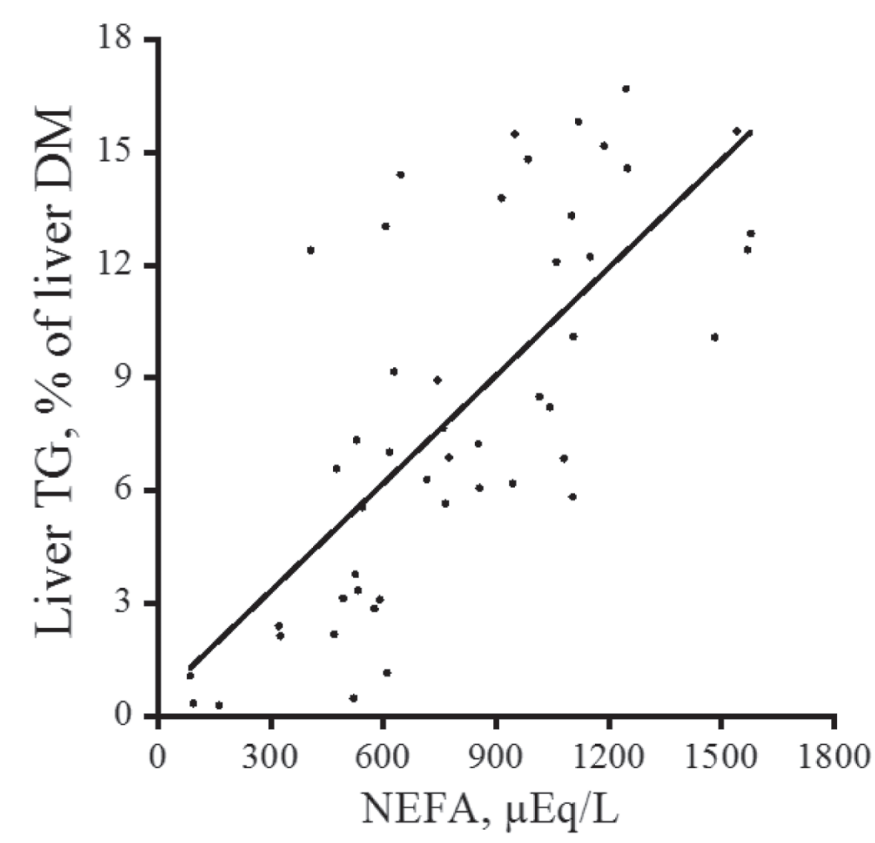

B

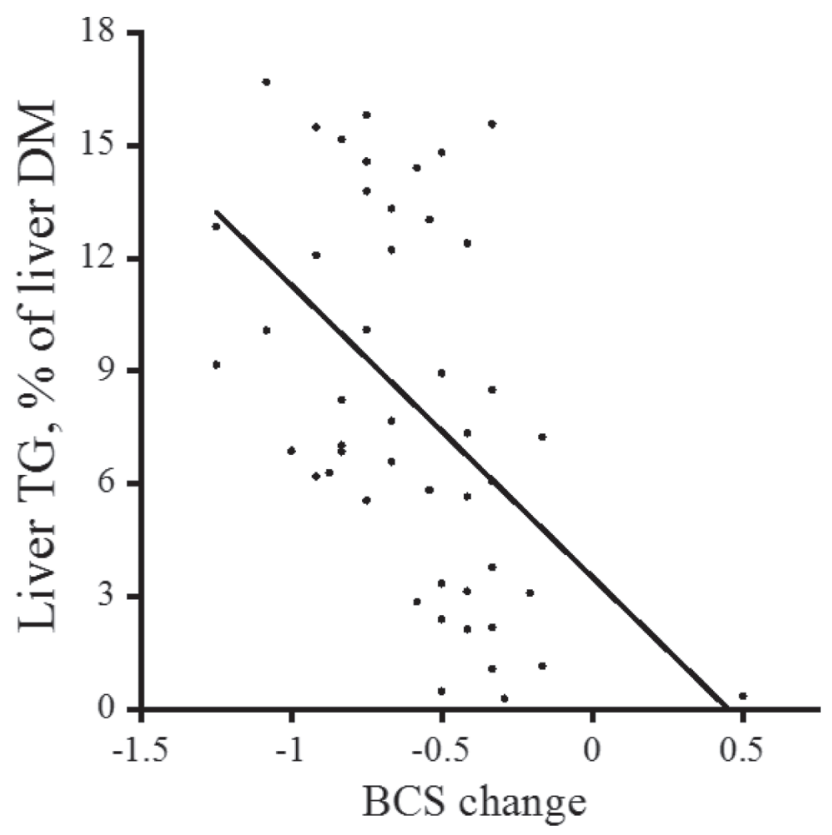

Figure 2. Relationship between liver triglyceride (TG) content and plasma NEFA concentration and BCS change between prepartum and $19 \pm 3$ d postpartum $(\mathrm{n}=48)$. (A) Relationship between liver TG content and plasma NEFA concentration [liver TG (\% of liver DM) $=0.459( \pm 1.18)+0.010( \pm 0.001) \times \mathrm{NEFA}(\mu \mathrm{Eq} / \mathrm{L}) ; \mathrm{R}^{2}=0.52 ; P<$ 0.0001]. (B) Relationship between liver TG content and BCS change [liver TG $(\%$ of liver DM $)=3.51( \pm 1.34)-7.78( \pm 1.99) \times$ BCS change; $\left.\mathrm{R}^{2}=0.25 ; P<0.001\right]$.

weeks PP might improve net energy intake and EBal (Jerred et al., 1990). However, experiments in the literature that have evaluated the effects of dietary forage level and fat supplementation around parturition on cow performance vary not only in the level of dietary forage and type of fat supplements fed, but also in days on treatment and stage of lactation of cows being supplemented (e.g., pre- and PP, only PP, early lactation), making it difficult to compare results. For example, Rabelo et al. (2003) showed that a lower F:C diet $(25 \% \mathrm{NDF})$ did not affect energy intake or EBal when fed during the first $70 \mathrm{~d}$ PP compared with a higher F:C diet (30\% NDF). Nevertheless, in that same experiment the lower $\mathrm{F}$ : $\mathrm{C}$ diet tended to increase DMI, and therefore, increased energy intake during the first 3 wk PP, which is consistent with Jerred et al. (1990) and our results with the lower fNDF diets during the first weeks PP. Unfortunately, Rabelo et al. (2003) did not calculate EBal for the first 3 wk PP. In terms of fat supplementation, Moallem et al. (2007) fed a saturated fat during the pre- and PP periods and reported that fat supplementation did not affect predicted energy intake or milk yield, but decreased predicted EBal PP compared with a diet with no supplemental fat. Consistent with these results, Beam and Butler (1998) showed that a saturated free FA supplement fed only during the immediate PP period did not affect predicted energy intake during the first 6 wk of lactation. However, in the current experiment we observed an increase in energy intake as well as EBal when feeding SFFA during the first weeks PP, regardless of dietary fNDF. Weiss and Pinos-Rodríguez (2009) reported an interaction among saturated free FA supplementation, dietary fNDF content, and time in early lactation cows: diets supplemented with saturated free FA increased predicted net energy intake in both high and low fNDF diets before cows reached peak milk, but lower fNDF diets increased predicted net energy intake after peak lactation regardless of fat supplementation. Overall, that experiment showed that saturated free FA supplementation and lower fNDF diets increased net energy intake from 21 to 126 d PP. Experiments mentioned indicate that feeding a higher energy dense diet do not always increase energy intake and improve EBal and that results observed in early lactation may not apply to cows in the immediate PP period.

Unfortunately, DEI was generally predicted from the diet and not actually measured in previous experiments with PP cows. Considering how variable DM digestibility among cows can be (Piantoni et al., 2013), predicting EBal using energy concentrations predicted from dietary composition is inadequate, and therefore, digestibility of nutrients was evaluated weekly in the current experiment. In the current experiment, SFFA supplementation increased measured DEI and EBal regardless of fNDF content of the diet. However, SFFA decreased BCS loss and did not affect milk $\mathrm{NE}_{\mathrm{L}}$ out- 
put, and therefore, SFFA supplementation decreased the efficiency of utilization of DEI for milk $\mathrm{NE}_{\mathrm{L}}$. Fat supplementation during the immediate PP increased energy partitioned to body reserves and not milk production, regardless of dietary fNDF content, but more so in the low fNDF diet. In contrast, high fNDF diets decreased DEI and EBal, but did not affect milk $\mathrm{NE}_{\mathrm{L}}$, increasing BCS loss, and therefore, efficiency of utilization of $\mathrm{NE}_{\mathrm{L}}$. Our hypothesis for metabolic responses to forage level and fat supplementation was based upon previous research with cows in early lactation in which treatments were initiated $21 \mathrm{~d}$ PP (Weiss and PinosRodríguez, 2009). However, production results in the current experiment with PP cows differ from those, and our hypothesis was not confirmed.

\section{Plasma Metabolites and Hormones}

The effect of SFFA on energy partitioning was consistent with a tendency for lower plasma NEFA concentrations, which suggests reduced lipolysis and fat mobilization. The difference in plasma NEFA concentration between 0 and $2 \%$ SFFA was greatest during the first week PP, when NEFA concentrations are highest in plasma (Contreras et al., 2010). Results are in contrast with previous studies in which saturated fat supplementation had no effect (Beam and Butler, 1998) or increased plasma NEFA concentrations during the PP period (Moallem et al., 2007). Although we did not detect an effect of SFFA supplementation on weekly plasma insulin concentrations, $2 \%$ SFFA increased baseline plasma insulin concentration by more than 50\% compared with 0\% SFFA for the GTT and ITT, and more so in the low fNDF diet for the ITT, consistent with the effect of SFFA on energy partitioning. The insulinotropic effect of long-chain saturated FA such as palmitic and stearic acids has been previously demonstrated in studies with perfused pancreas of fasted rats (Stein et al., 1997) and in vivo in cows (Harvatine and Allen, 2006; Piantoni et al., 2013). Inconsistency in plasma insulin concentrations between weekly samples and baseline values for GTT and ITT could be explained by the different times of the day relative to feeding in which these samples were taken: weekly samples were taken within $1 \mathrm{~h}$ before feeding, whereas samples for baseline values for GTT and ITT were taken $\sim 3 \mathrm{~h}$ before feeding. The effect of high fNDF diets on energy partitioning was supported by increased plasma NEFA and BHBA concentrations and decreased plasma insulin and glucose concentrations and insulin to glucagon ratio. The effects of fNDF treatment on glucose, insulin, and BHBA plasma concentrations are consistent with those reported by Rabelo et al. (2005) in PP cows. However, dietary NDF content had no effect on plasma NEFA concentration in that experiment.

\section{Liver Total Lipid, Triglycerides, and Glycogen Contents}

A higher dietary starch content during the PP period, when intense lipomobilization in dairy cows usually occurs, tended to decrease liver TG content at d $21 \mathrm{PP}$, despite the lack of an effect on plasma NEFA concentrations (Rabelo et al., 2005) or BW loss (Rabelo et al., 2003). In agreement with Rabelo et al. (2005), our results indicate that lower fNDF diets reduced liver total lipids and TG contents, which in our case were related to a tendency for a decrease in BCS loss. Results in the literature are inconsistent regarding the effect of fat supplementation on liver parameters. Supplementing a saturated fat during the transition period decreased liver TG content, plasma NEFA concentrations, and plasma aspartate aminotransferase activity, an indicator of liver health, in PP cows compared with a control diet with no supplemental fat (Karcagi et al., 2010). In contrast, supplementation of a saturated fat during the transition period did not affect liver TG contents, BW, or BCS during this period, even though it tended to decrease plasma NEFA concentration PP (Ballou et al., 2009). In our experiment, $2 \%$ SFFA tended to decrease BCS loss from parturition to $19 \mathrm{~d}$ PP, but did not decrease liver total lipid or TG content. Interestingly, a lipogenic diet fed during the transition period increased liver TG during the PP period but had no effect on BW loss compared with a glucogenic diet (van Knegsel et al., 2007). A higher starch diet is therefore more likely to decrease liver total lipids and TG than supplemental fat, which is consistent with our results.

\section{Insulin and Glucose Tolerance Tests}

Insulin resistance of extra-hepatic tissues develops during late pregnancy and persists during early lactation, and this is accompanied by a decrease in pancreatic insulin secretion (Bell, 1995; Zachut et al., 2013). To our knowledge, no experiments have evaluated the effects of saturated free FA supplementation and diets with different fNDF contents on responses to ITT or GTT in PP cows. In our experiment, after the glucose infusion, the low fNDF diet with $2 \%$ SFFA increased plasma insulin concentration to the greatest extent and at a faster rate compared with the other diets, which could indicate superior pancreatic insulin secretion capacity in these cows. Also, the lower fNDF diet with $2 \%$ SFFA increased AUC for insulin the most during the GTT. The effects of saturated free FA supplementation 
in the lower fNDF diet on insulin response were likely responsible for plasma glucose concentrations reaching baseline values faster compared with the other diets during the GTT. Consistent with our results, Pires et al. (2007) reported that maximum insulin and insulin AUC were higher in nonlactating, nongestating cows infused with tallow than in cows infused with saline during a GTT.

During the ITT, SFFA supplementation decreased the absolute value of the glucose response AUC, which indicates decreased insulin sensitivity from extrahepatic tissues, and therefore, less glucose utilization. Intravenous infusions of tallow also reduced glucose response during an ITT, compared with saline infusions in nonlactating nonpregnant cows (Pires et al., 2007) as well as in nonlactating late-gestation cows (Salin et al., 2012). Also similar to what was observed in our experiment, Pires et al. (2007) showed that tallow infusion increased basal plasma insulin concentrations, but did not affect insulin response during the ITT. Responses to GTT and ITT observed by Pires et al. (2007) and Salin et al. (2012) indicate that tallow infusion may have caused insulin resistance in cows, and researchers concluded that this was likely due to increased plasma NEFA concentrations. Even though in our experiment SFFA supplementation elicited similar glucose and insulin responses to GTT and ITT to those observed by Pires et al. (2007), they were not associated with higher plasma NEFA concentrations measured within $1 \mathrm{~h}$ before feeding. In laboratory animals, saturated FA increased adipose tissue expansion, inducing insulin resistance, and impairing insulin signaling (Kennedy et al., 2009). These effects on metabolism are consistent with our results with the tolerance tests and might also explain why insulin baseline concentrations were enhanced, because plasma insulin concentrations generally increase to compensate for increased insulin resistance. However, cows with greater insulin resistance might be expected to have greater response in milk yield, which is opposite to what happened when cows were supplemented fat in the lower fNDF diet. Although supplemental saturated free FA might have increased insulin resistance of tissues, the elevated plasma insulin concentration when combined with the higher starch (low fNDF) diet might have reduced net lipolysis and loss of body reserves at the expense of milk yield.

During the GTT, low fNDF diets, with greater starch content, resulted in greater insulin secretion compared with high fNDF diets. This was demonstrated by increased insulin maximum, the rate at which insulin increased, and insulin AUC. During the GTT, glucose AUC was lower for lower fNDF diets, indicating faster clearance from blood likely related to increased insulin sensitivity of tissues and not greater secretion in milk, because milk production in these cows was not significantly different from those on the higher fNDF diet. Moreover, during the ITT, low fNDF diets decreased plasma glucose concentration at a faster rate than high fNDF diets, also indicating higher insulin responsiveness from insulin sensitive tissues.

\section{CONCLUSIONS}

In a companion article, we showed that feeding $2 \%$ SFFA in a lower fNDF diet during the first $29 \mathrm{~d}$ PP affected energy partitioning, decreasing BCS loss during the treatment period and $3.5 \%$ FCM yield in the carryover period. Data presented in this article indicate that effects on energy partitioning observed in the lower fNDF diet with $2 \%$ SFFA might be related to an increase in plasma insulin concentration. Even though feeding a highly saturated free FA supplement in the $\mathrm{PP}$ period increased EBal and DEI, especially in the lower fNDF diet, it did not affect liver TG content. A lower fNDF diet during the PP period not only improved EBal and plasma metabolic and hormonal profile, but also decreased liver TG content. Both $2 \%$ SFFA supplementation and lower fNDF diets increased insulin secretion, and insulin resistance of tissues was likely increased by $2 \%$ SFFA and decreased by lower fNDF. Feeding a highly saturated free FA supplement during the PP period in a low fNDF diet might have primed the cows to limit fat mobilization apparently at the expense of milk, making it difficult to justify their use in similar diets during this period.

\section{ACKNOWLEDGMENTS}

We acknowledge Milk Specialties Global (Eden Prairie, MN) and Michigan State University AgBioResearch (East Lansing, MI) for financial support of this research. We also thank D. G. Main, R. A. Longuski, C. L. Preseault, S. E. Stocks, W. E. Brown, R. J. Rabczak, R. E. Kreft (all from Michigan State University), and the staff of the Michigan State University Dairy Cattle Field Laboratory (East Lansing) for their assistance in this experiment.

\section{REFERENCES}

Allen, M., B. Bradford, and M. Oba. 2009. BOARD-INVITED REVIEW: The hepatic oxidation theory of the control of feed intake and its application to ruminants. J. Anim. Sci. 87:3317-3334.

Allen, M. S., and P. Piantoni. 2013. Metabolic control of feed intake: Implications for metabolic disease of fresh cows. Vet. Clin. North Am. Food Anim. Pract. 29:279-297.

Ballou, M. A., R. C. Gomes, S. O. Juchem, and E. J. DePeters. 2009. Effects of dietary supplemental fish oil during the peripartum period on blood metabolites and hepatic fatty acid compositions and 
total triacylglycerol concentrations of multiparous Holstein cows. J. Dairy Sci. 92:657-669.

Beam, S. W., and W. R. Butler. 1998. Energy balance, metabolic hormones, and early postpartum follicular development in dairy cows fed prilled lipid. J. Dairy Sci. 81:121-131.

Bell, A. 1995. Regulation of organic nutrient metabolism during transition from late pregnancy to early lactation. J. Anim. Sci. 73:2804-2819.

Bernal-Santos, G., J. W. Perfield II, D. M. Barbano, D. E. Bauman, and T. R. Overton. 2003. Production responses of dairy cows to dietary supplementation with conjugated linoleic acid (CLA) during the transition period and early lactation. J. Dairy Sci. $86: 3218-3228$.

Bligh, E. G., and W. J. Dyer. 1959. A rapid method of total lipid extraction and purification. Can. J. Biochem. Physiol. 37:911-917.

Bradford, B., and M. S. Allen. 2007. Depression in feed intake by a highly fermentable diet is related to plasma insulin concentration and insulin response to glucose infusion. J. Dairy Sci. 90:3838 3845.

Bradford, B., A. Gour, A. Nash, and M. Allen. 2006. Propionate challenge tests have limited value for investigating bovine metabolism. J. Nutr. 136:1915-1920.

Contreras, G. A., N. J. O'Boyle, T. H. Herdt, and L. M. Sordillo. 2010. Lipomobilization in periparturient dairy cows influences the composition of plasma nonesterified fatty acids and leukocyte phospholipid fatty acids. J. Dairy Sci. 93:2508-2516.

González, F. D., R. Muiño, V. Pereira, R. Campos, and J. L. Benedito. 2011. Relationship among blood indicators of lipomobilization and hepatic function during early lactation in high-yielding dairy cows. J. Vet. Sci. 12:251-255.

Harvatine, K., and M. Allen. 2006. Effects of fatty acid supplements on milk yield and energy balance of lactating dairy cows. J. Dairy Sci. 89:1081-1091.

Hawk, P. B., and O. Bergeim. 1926. Practical Physiological Chemistry. 9th ed. Maple Press Co., York, PA.

Jerred, M. J., D. J. Carrol, D. K. Combs, and R. R. Grummer. 1990 Effects of fat supplementation and immature alfalfa to concentrate ratio on lactation performance of dairy cattle. J. Dairy Sci. 73:2842-2854.

Karcagi, R. G., T. Gaál, P. Ribiczey, G. Huszenicza, and F. Husvéth 2010. Milk production, peripartal liver triglyceride concentration and plasma metabolites of dairy cows fed diets supplemented with calcium soaps or hydrogenated triglycerides of palm oil. J. Dairy Res. 77:151-158.

Kennedy, A., K. Martinez, C. C. Chuang, K. LaPoint, and M. McIntosh. 2009. Saturated fatty acid-mediated inflammation and insulin resistance in adipose tissue: Mechanisms of action and implications. J. Nutr. 139:1-4.

Lacetera, N., D. Scalia, O. Franci, U. Bernabucci, B. Ronchi, and A. Nardone. 2004. Short Communication: Effects of nonesterified fatty acids on lymphocyte function in dairy heifers. J. Dairy Sci. 87:1012-1014

Moallem, U., M. Katz, H. Lehrer, L. Livshitz, and S. Yakoby. 2007. Role of peripartum dietary propylene glycol or protected fats on metabolism and early postpartum ovarian follicles. J. Dairy Sci. $90: 1243-1254$
NRC. 2001. Nutrient Requirements of Dairy Cattle. 7th rev. ed. National Academy Press, Washington, DC.

Piantoni, P., A. L. Lock, and M. S. Allen. 2013. Palmitic acid increased yields of milk and milk fat and nutrient digestibility across production level of lactating cows. J. Dairy Sci. 96:7143-7154.

Piantoni, P., A. L. Lock, and M. S. Allen. 2015. Saturated fat supplementation interacts with dietary forage NDF concentration during the immediate postpartum and carryover periods in Holstein cows: Production responses and digestibility of nutrients. J. Dairy Sci. 98:3309-3322. 10.3168/jds.2014-8798.

Pires, J. A. A., A. H. Souza, and R. R. Grummer. 2007. Induction of hyperlipidemia by intravenous infusion of tallow emulsion causes insulin resistance in Holstein cows. J. Dairy Sci. 90:2735-2744.

Rabelo, E., R. L. Rezende, S. J. Bertics, and R. R. Grummer. 2003. Effects of transition diets varying in dietary energy density on lactation performance and ruminal parameters of dairy cows. J. Dairy Sci. 86:916-925.

Rabelo, E., R. L. Rezende, S. J. Bertics, and R. R. Grummer. 2005. Effects of pre-and postfresh transition diets varying in dietary energy density on metabolic status of periparturient dairy cows. J. Dairy Sci. 88:4375-4383

Rice, B. H., J. Kraft, F. Destaillats, D. E. Bauman, and A. L. Lock. 2010. Ruminant-produced trans-fatty acids raise plasma total and small HDL particle concentrations in male Hartley guinea pigs. J. Nutr. 140:2173-2179.

Salin, S., J. Taponen, K. Elo, I. Simpura, A. Vanhatalo, R. Boston, and T. Kokkonen. 2012. Effects of abomasal infusion of tallow or camelina oil on responses to glucose and insulin in dairy cows during late pregnancy. J. Dairy Sci. 95:3812-3825.

Smith, K. L., S. E. Stebulis, M. R. Waldron, and T. R. Overton. 2007. Prepartum 2,4-thiazolidinedione alters metabolic dynamics and dry matter intake of dairy cows. J. Dairy Sci. 90:3660-3670.

Sordillo, L. M., G. A. Contreras, and S. L. Aitken. 2009. Metabolic factors affecting the inflammatory response of periparturient dairy cows. Anim. Health Res. Rev. 10:53-63.

Stein, D., B. Stevenson, M. Chester, M. Basit, M. Daniels, S. Turley, and J. McGarry. 1997. The insulinotropic potency of fatty acids is influenced profoundly by their chain length and degree of saturation. J. Clin. Invest. 100:398-403

van Knegsel, A. T. M., H. van den Brand, J. Dijkstra, W. M. van Straalen, R. Jorritsma, S. Tamminga, and B. Kemp. 2007. Effect of glucogenic vs. lipogenic diets on energy balance, blood metabolites, and reproduction in primiparous and multiparous dairy cows in early lactation. J. Dairy Sci. 90:3397-3409.

Weiss, W. P., and J. M. Pinos-Rodríguez. 2009. Production responses of dairy cows when fed supplemental fat in low- and high-forage diets. J. Dairy Sci. 92:6144-6155.

Wildman, E. E., G. M. Jones, P. E. Wagner, R. L. Boman, H. F. Troutt Jr., and T. N. Lesch. 1982. A dairy cow body condition scoring system and its relationship to selected production characteristics. J. Dairy Sci. 65:495-501.

Zachut, M., H. Honig, S. Striem, Y. Zick, S. Boura-Halfon, and U. Moallem. 2013. Periparturient dairy cows do not exhibit hepatic insulin resistance, yet adipose-specific insulin resistance occurs in cows prone to high weight loss. J. Dairy Sci. 96:5656-5669. 